\title{
GUEST EDITORIAL Are we being seduced by a robot?
}

\section{J. Curtis Nickel, MD, FRCSC}

Professor of Urology, Queen's University, Kingston General Hospital, Kingston, ON
Editor's note: This journal is of the people, by the people, and for the people. To this end, we are introducing guest editorials by opinion leaders in Canada and throughout the world. In this issue, J. Curtis Nickel's editorial attacks the robotics phenomenon with a vengeance. His provocative article will evoke strong reactions from colleagues on both sides of the issue. It is as cogent and strongly argued a piece as I have seen on this critically important question.

There are a number of unusual and interesting articles in this issue. Mickelson, Kaplan and MacNeily describe the "accidental" development of a student-centred urology curriculum involving active learning and the high satisfaction of residents and staff with this program. Is this a model for the country? Perhaps.

Gagnon, Simard and Tu assess the knowledge level of the population in Quebec and Vermont about what urologists do. Unsurprisingly, the survey revealed a profound lack of familiarity with our domain. Insofar as public awareness leads to support for resource allocation, I agree with the authors that urology would benefit from greater public knowledge of how we contribute to the health and welfare of the population. Richard Casey, however, takes a strikingly different view. He argues that this really doesn't matter. Indeed, he claims that the common confusion between urology and neurology extends to his own mother.

Whatever your opinion is on this issue and the other topics covered in this edition, we welcome your opinion and feedback. Please email us with your views at josephine.sciortino@cua.org.

Laurence Klotz, Editor-in-Chief, CUAJ

M y partner was seduced by a robot! An excellent physician, great laparoscopic surgeon and blossoming academic urologist was lured from a "people-orientated" academic practice group by an impersonal machine of cold steel, gears and circuits. I realize that my younger colleagues embrace Facebook and Twitter as a means of social intercourse, but how does a technological automaton in another province affect my practice and my profession?

Are these dehumanizing techno-idols the future of our profession? In a recent article in JAMA, Leff and Finucane explored the "gizmo idolatry" that has swept not only urology, but the entire medical profession. ${ }^{1}$ They argue against the general implicit conviction that a more technological approach is intrinsically better than one that is less technological; there actually is strong evidence to the contrary. What are the factors promoting this techno-envy that has gripped my colleagues, making them do almost anything to belong to this new "robot club"? I am absolutely sure that it cannot be only the "bells and whistles" associated with robotic surgery; it's certainly not overall better outcomes, quicker surgery or even reduced costs. I think it is the nebulous allure of new technology that drives us from our usual rational assessment of cost and benefits. They believe it confers on them a sense that they are truly on the "cutting edge" of our profession.

The robot is certainly not about patient care, unless giving the patient what he thinks he wants based on advertisements and promotion is a part of our patient care mandate. It's certainly not about costs, since no one in Canada (or the U.S. for that matter) has ever been able to make a business plan that has the robot saving the healthcare system money. And perhaps there is even harm, in terms of our duty to the public trust, in our fanatical rush to get in line for a new robot. In a potent analogy of the Titanic and the iceberg, Anthony Zietman recently pointed out that when the unpredictable yet completely avoidable collision came, it was the hubris of technology that fared worse. ${ }^{2}$ I believe we are about to witness a collision between the robotic haves and the robotic have-nots. The robotic advocates will be driven by powerful market forces, high-stakes investment and advertising, while those who will never own a robot 
will only have the hard, cold and unyielding laws of nature and economics to support them. Can or even should we do something to change our destiny?

We do have to acknowledge that the robot is not an experimental therapy but a legitimate form of treatment for localized prostate cancer that has some theoretical advantages over non-robotic surgery. But before we become enraptured with this approach, we must examine the benefits and the costs. No one has been able to convince me that patients operated on with a robot end up with a significantly better longterm outcome in terms of eventual cure and/or morbidity compared to standard open and/or laparoscopic procedures. The only surgically related argument my colleagues who have embraced the robot have told me is that it is sexier, more fun and easier. Seduction may be easy, fun and gratifying, but succumbing has a price-particularly if the seductress' virtues are questionable. If however, the benefits are shown to be so obvious that all patients requiring prostate surgery must ethically have it done with a robot, we must then pay for it out of available resources, perhaps regionalizing robots in geographical centres of robotic excellence. If however, the costs are too high for the perceived benefits, then we must decide not to be lured on to this bandwagon. Our idolatry of robotic technology could lead to a significant distortion of health care, a draining of scarce financial and urological resources, a redirection of hospital priorities and budgets, possible over-treatment of patients and perhaps, eventually, problems in training urological surgeons for a non-robotic environment.

I do not believe that only urologists with a robot can claim expertise, competence and pre-eminence in our profession. A combination of avarice, heroism, credulity and idolatry has imparted considerable momentum to the early adoption of this exciting technology in Canada. The robot has really seduced us. Like many affairs, we may wake up some morning and realize that the cost of our infatuation may not have been ultimately worth it. Although I now understand our fascination and idolatry with the machine and fully realize the dangers to myself and my profession, I, too, am enamoured of and even bewitched by the robot. If the mechanical lady comes calling, I fear I could be seduced as well.

\section{References}

1. Leff B, Finucane TE. Gizmo Idolatry. JAMA 2008;299:1830-2.

2. Zietman AL. The Titanic and the Iceberg: Prostate Proton Therapy and Health Care Economics. I Clin Oncol 2007;25:3566-7. 